\title{
Epistaxis in Kaduna, Nigeria: a review of 101 cases
}

\author{
*Kodiya AM, Labaran AS, Musa E, Mohammed GM, Ahmad BM
}

National Ear Care Centre, Golf Course Road, by Independence Way, Kaduna, Nigeria

\begin{abstract}
Background: Epistaxis is defined as a hemorrhage from the nostril, nasal cavity, or nasopharynx. Sufferers and clinicians may develop significant anxiety despite the fact that majority of patients are treated successfully by the first attending physician.

Objective: To review aetiology and management outcomes of epistaxis in a resource constrained setting.

Methodology: A retrospective review of 101 patients seen with epistaxis at the National Ear Care Centre, Kaduna over 7years (January 2002- December 2008).

Results: The age of patients ranged between 2 and $75 y$ years. The incidence of epistaxis of $0.5 \%$ was recorded out of total patient visit and slight male preponderance with a male:female ratio of 1.4:1. Dry-hot and cold harmattan weather had the highest prevalence. Trauma and infections were the main aetiological factors identified but over $40 \%$ of cases are idiopathic in origin. About $25 \%$ presented with active bleeding and $11 \%$ required admission. All were managed conservatively. Less than $2 \%$ received blood transfusion.

Conclusion: Epistaxis is a common emergency that requires prompt intervention to reduce further morbidity and prevent mortality. Non operative intervention was a satisfactory approach in this study.

Key words: Epistaxis, resource constrained, conservative management.

African Health Sciences 2012; (4): 479 - 482 http://dx.doi.org/10.4314/ahs.v12i4.13
\end{abstract}

\section{Introduction}

Bleeding from the nose and nasopharynx is a common feature of diverse conditions. It may present as mild recurrent bleeds or severe life threatening emergency and posing a challenge to even a skilled otolaryngologist $\mathrm{t}^{1}$

The true incidence remains unknown. It is estimated that $60 \%$ of the population will have at least one episode of epistaxis in their life time and $6 \%$ of them will seek medical attention ${ }^{2}$. A slight male preponderance (55\% male and $45 \%$ female) has been reported ${ }^{1-3}$. Epistaxis is rare in neonates but common among children and young adults and peaks in the sixth decade giving a bi-modal age distribution ${ }^{2,3}$. It is more common in the cold winter and during the hot dry climate.

The nasal mucosa is richly supplied by branches of both external and internal carotid arteries with abounding anastomoses. The Kiesselbachs plexus is responsible for 85 - 95\% of anterior epistaxis but easy to identify and treat. Posterior epistaxis which constitutes $5-15 \%$ is often more severe, difficult to locate and treat ${ }^{3}$. A structured

\begin{tabular}{l} 
*Corresponding author: \\
Aliyu M. Kodiya \\
National Ear Care Centre \\
Golf course road, Independence way \\
Kaduna, Nigeria \\
Email: dockodiya@yahoo.com \\
\hline
\end{tabular}

African Health Sciences Vol 12 Issue 4 December 2012 clinical classification of epistaxis into primary or secondary, childhood or adult and anterior or posterior is preferred over the traditional classification based on local and systemic causes ${ }^{3}$. This is because majority of cases have no identifiable aetiological factors.

The goals of therapy in epistaxis are to control haemorrhage, reduce hospital stay and limit complications in a cost effective way. The best treatment modality to achieve these goals is however a matter of great debate ${ }^{1,2}$. Resuscitation where indicated is mandatory. Specific treatment can be conservative or surgical. Conservative methods include cauterization (electrical and chemical) and nasal packing. Traditional surgical methods are ligation of feeding vessels while modern approaches include endoscopic ligation and embolization. We present our experience in managing epistaxis in a resource constrained setting.

\section{Methods}

This is a retrospective review of 101 patients seen over a period of 7years between January 2002 and December 2008 at the National Ear Care Centre, Kaduna, Nigeria. This period coincided with the time when the Centre was constrained in terms of adequate personnel, facilities and other resources. It was being operated on three different borrowed spaces. There was a complex for administration 
which was about three $(3 \mathrm{Km})$ kilometers from a limited space in a Hospital for clinics and admission and another Hospital for Theatre space located between the two spaces above.

Out- patient and in- patient registers were used. Parameters extracted include demographics, month of presentation, trigger of bleeding, concomitant medical conditions, drug history, examination findings, treatment modality, complications, and length of hospital stay. The data were analyzed using simple descriptive statistical methods.

\section{Results}

A total of 20,308 patients were seen at our centre during the period under review. Of this number, 101 patients $(0.5 \%)$ had epistaxis as a presenting complaint. About $1 / 4$ of the patients (25) presented with active bleeding while 76 presented with recurrence.

Figure 1 shows age distribution of patients. Age ranged from 2 to 75 years, with mean age of 30.4 years. Modal age presentations were recorded among age groups $1-20$ years $(40.6 \%)$ and $31-40$ years $(33.6 \%)$.

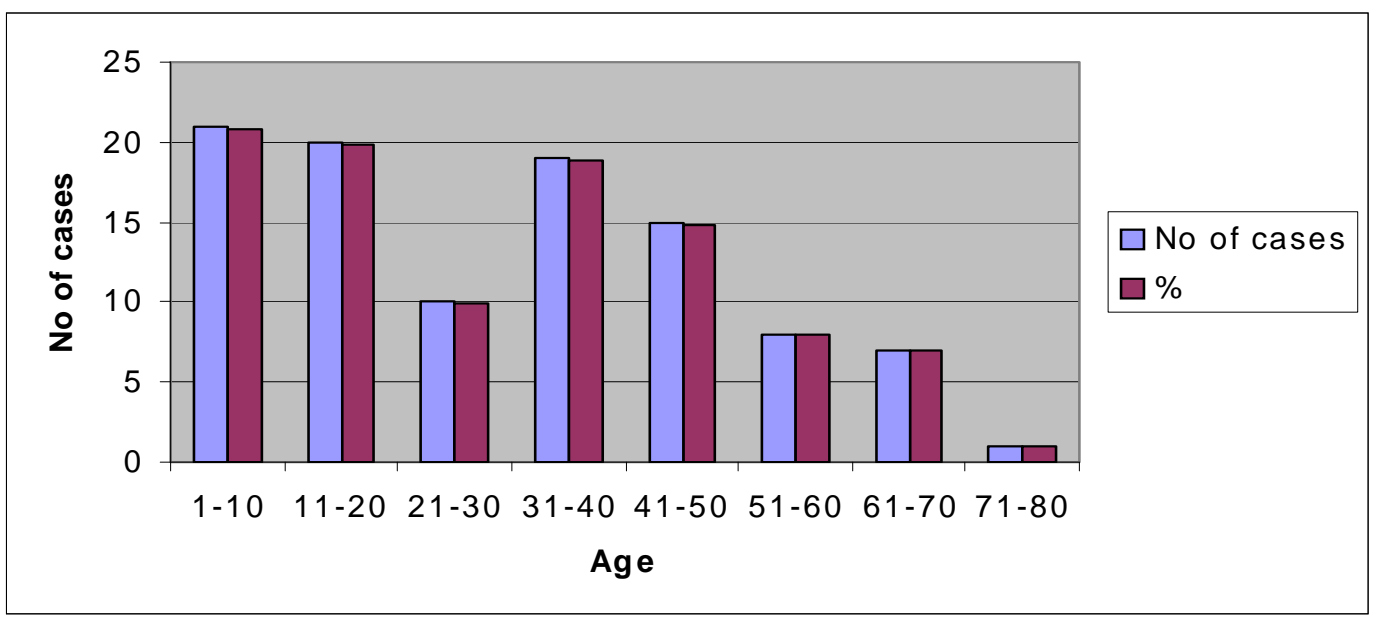

Figure 1: Age distribution of patients

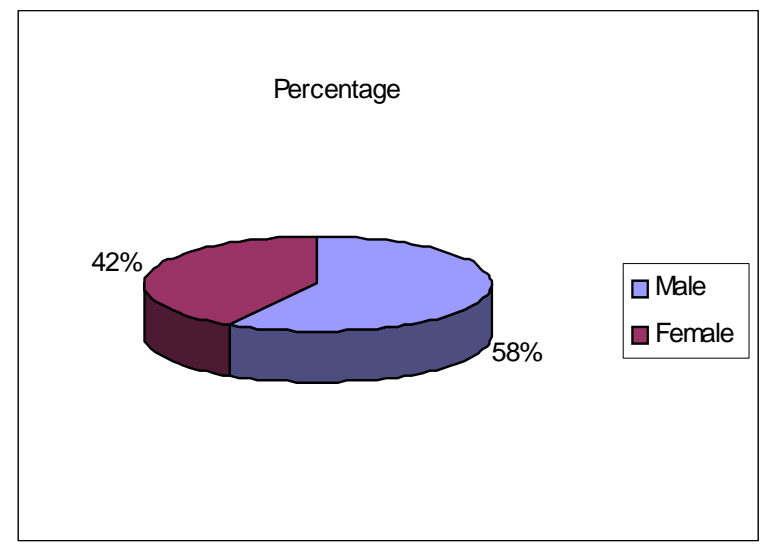

Figure 2: Distribution by sex

Table 1 shows peaks at April (hot weather) and October to December (cold dry weather) with only $4 \%$ presenting in May. Only 11 patients $(10.89 \%)$ required admission. Of these, 2 received blood transfusion. The average hospital stay was 3 days.
Table 1: Distribution by month of presentation

\begin{tabular}{ll}
\hline Month of the year & No. of cases (\%) \\
\hline January & $8(7.92)$ \\
February & $6(5.94)$ \\
March & $8(7.92)$ \\
April & $11(10.89)$ \\
May & $4(3.96)$ \\
June & $5(4.95)$ \\
July & $9(8.91)$ \\
August & $7(6.93)$ \\
September & $6(5.94)$ \\
October & $13(12.87)$ \\
November & $14(13.86)$ \\
December & $10(9.91)$ \\
\hline
\end{tabular}

Table 2 shows the associated aetiological factors. Unknown aetiology accounts for $45.5 \%$ followed by trauma (15.8\%) and infection (11.9\%).

Table 3 shows management of 25 patients who presented with active epistaxis. Of treated patients $52 \%$ had anterior nasal pack, $16 \%$ had both anterior and posterior nasal packs while $32 \%$ benefitted from cautery. 
Table 2: Distribution by aetiologic factor

\begin{tabular}{ll}
\hline Aetiological factors & $\begin{array}{l}\text { No. of patients } \\
\text { (Percentage) }\end{array}$ \\
\hline Idiopathic & $45(45.55)$ \\
Trauma & $16(15.84)$ \\
Hypertension & $13(12.87)$ \\
Sinonasal infections & $12(11.88)$ \\
Sinonasal Tumours & $5(4.95)$ \\
Blood dyscrasia & $4(3.96)$ \\
Chronic liver disease & $3(2.97)$ \\
Nasal Foreign body & $1(0.99)$ \\
Drug induced & $1(0.99)$ \\
Deviated nasal septum & $1(0.99)$ \\
Total & $101(100)$ \\
\hline
\end{tabular}

Table 3: Treatment modalities

\begin{tabular}{ll}
\hline Treatment Modality & $\begin{array}{l}\text { No. of } \\
\text { Cases (\%) }\end{array}$ \\
\hline Anterior nasal packing & $13(52)$ \\
Anterior and posterior nasal packing & $4(16)$ \\
Cauterization & $8(32)$ \\
Total & $25(100)$ \\
\hline
\end{tabular}

\section{Discussion}

Epistaxis is a common presentation in Ear, Nose and Throat (ENT) practice ${ }^{1-4}$. In this study the incidence was $0.5 \%$. The age ranged from 2 to 75 years with the mean age of 30.49years. Male to female ratio was 1.4:1. These findings are in agreement with the study of Mgbor ${ }^{1}$ carried out in Enugu, south eastern Nigeria. Bimodal age presentation with peaks at age groups 1-20 years and 31-40 years was observed. Adult epistaxis has been reported to be commoner in the sixth decade of life ${ }^{2,3}$ In this study however adult epistaxis was found to be commoner in the forth decade of life. Perhaps it is so because of relative low life expectancy in the tropics thus the small number of elderly patients. Increased incidence of epistaxis in cold harmattan months and hot / dry months has been reported ${ }^{3}$ agreeing with our findings. This is in agreement with the report of Bhathia ${ }^{5}$ in Jos who attributed the increased incidence to high wind velocity and dryness which favor crust formation in the nasal cavity.

A committed search for the bleeder as well as a deliberate effort to find the cause of epistaxis ${ }^{3,6,7}$ is necessary, because too many cases of epistaxis are grouped as idiopathic or primary. In this study $45.55 \%$ of cases were idiopathic similar to findings of Mgbor. ${ }^{1}$ It may likely decrease with more

African Health Sciences Vol 12 Issue 4 December 2012 resources/better equipment and careful examination. Trauma, infections and tumors were common known factors. Saurabh reported cardiovascular diseases (including hypertension and arteriosclerosis), infection and trauma in decreasing importance as leading causes of secondary epistaxis. In this series about $13 \%$ of patients had hypertension without any other identifiable cause of epistaxis, but it was observed that 3 patients who had epistaxis secondary to trauma and 1 patient due to blood dyscrasias also had hypertension. Bleeding was more severe among patients with hypertension however there is no causal relationship between hypertension and epistaxis. It is possible that with the committed search one could find the real cause of epistaxis in these patients. Elima ${ }^{8}$ reported that epistaxis is unlikely to be a hypertensive emergency and a number of large studies have failed to show causal relationship between hypertension and epistaxis ${ }^{9}$

If found the bleeding site is cauterized either with silver nitrate or electro cautery. Failure to find the bleeding point leads to anterior nasal pack with paraffin gauze, gloved finger or merocele when available. Fifty two percent of our patients were successfully managed with anterior nasal packs alone. In $16 \%$ of patients with posterior nasal pack using Foleys catheter inflated with air in addition to anterior nasal pack with paraffin gauze under local anaesthesia. All patients with nasal packs were given prophylactic antibiotics. Nasal packs were removed after $24-48$ hours; no pack related complications were recorded. Most patients were discharged on third day of admission. There was no mortality recorded, similar to Urashi et $\mathrm{al}^{10}$.

Epistaxis is a common presentation often as recurrent minor bleeds but not infrequently as acute severe episode requiring emergency care. Thorough patient evaluation is mandatory for appropriate management. More purposeful search for etiological factors by the attending physician and identification of bleeding point must be encouraged. Some of the constraints during the period under review were that of inadequate personnel, space, lack of equipments and funds for logistics. Conservative management was very effective despite resource constraint. Inspite of the anxiety generated by nose bleeding, cure can be achieved by the first attending physician if prompt and appropriate intervention is made. 


\section{References}

1. Mgbor NC. Epistaxis in Enugu: A 9 year Review. Nig J of otolaryngology 2004; 1(2):11-14.

2. Varshney S, Saxena RK: Epistaxis: a retrospective clinical study. Indian Journal of Otolaryngology, Head Neck Surgery 2005, 57:125-129.

3. Watkinson JC. Epistaxis In: Scott-Brown's Otorhinolaryngology $6^{\text {th }}$ ed. Vol. 4, Oxford Boston: Butterworth-Heinemann; 1997: 4/18/ 1-17.

4. Ijaduola GTA, Okeowo PA. Pattern of epistaxis in the tropics. Centr Afr J Med 1983:29-80.

5. Bhatia PL, Varughese R. Pattern of otolaryngological diseases in Jos community. Niger Med J 1987; 17: 67-73.

6. O’Donnell M, Robertson G, McGarry GW. A new bipolar diathermy probe for the outpatient management of adult acute epistaxis. Clinical Otolaryngology 2001; 24: 537-41.
7. Holder Juselius. Epistaxis: a clinical study of 1,724 patients: The Journal of Laryngology and Otology 1974, 88: 317-327.

8. E. Lima Jr and J. Knopfholz: C030: Relationship between epistaxis and arterial pressoric blood levels: is the epistaxis a hypertensive emergency? Am J Hypertens 2000; 13: 220A-220A.

9. Lubianca-Neto, Jose F, Bredemeier M, Carvalhal Eduardo F, Arruda Cristina A, Eduardo E, et al. A study of the association between epistaxis and the severity of hypertension. American Journal of Rhinology 1998; 12 (4): 269-272.

10. Urvashi R, Raizada RM. and Chaturvedi VN. Efficacy of conservative treatment modalities used in epistaxis, Indian Journal of Otolaryngology and Head \& Neck Surgery. 2004; 56 (1): 20-22. 